\title{
Association between 5-hydroxytryptamine transporter gene-linked promoter region polymorphism and the susceptibility of lifelong premature ejaculation: a meta-analysis involving 1,604 subjects
}

\author{
Kechong Zhou", Yuxuan Song", Yi Lu, Yongjiao Yang, Xiao Wang, Kang Liu, Xiaoqiang Liu \\ Department of Urology, Tianjin Medical University General Hospital, Tianjin 300052, China \\ Contributions: (I) Conception and design: K Zhou, Y Song; (II) Administrative support: K Zhou, Y Song; (III) Provision of study materials or patients: \\ K Zhou, Y Lu; (IV) Collection and assembly of data: K Zhou, Y Song, Y Yang, X Wang; (V) Data analysis and interpretation: K Zhou, Y Song, Y Lu, \\ K Liu, X Liu; (VI) Manuscript writing: All authors; (VII) Final approval of manuscript: All authors. \\ "These authors contributed equally to this work. \\ Correspondence to: Xiaoqiang Liu. Department of Urology, Tianjin Medical University General Hospital, 154 Anshan Road, Heping District, Tianjin \\ 300052, China. Email: liutmugh@163.com.
}

\begin{abstract}
The relationship between 5-hydroxytryptamine transporter-linked promoter region (5-HTTLPR) gene and lifelong premature ejaculation (LPE) risk was discussed widely for the last few years, which was still controversial and remained to be explored. We performed the meta-analysis with 8 reliable research, which were searched in the following databases: PubMed, Embase and Cochrane Library. We also performed random and fixed effects models to evaluate the odds ratios (ORs) and $95 \%$ confidence intervals respectively. By pooling all included studies, we found that SS genotype of 5-HTTLPR polymorphism was linked with significantly higher PE risk in Caucasian population (OR $=0.635,95 \%$ CI: $0.417-0.958, \mathrm{I}^{2}=0.311$, $\mathrm{P}=0.035)$, and $\mathrm{S}$-allele of 5-HTTLPR polymorphism increased the risk of LPE significantly in Asian population $\left(\mathrm{OR}=0.656,95 \% \mathrm{CI}\right.$ : $\left.0.539-0.799, \mathrm{I}^{2}=0.435, \mathrm{P}<0.001\right)$. However, no significant was observed between 5-HTTLPR gene polymorphism and LPE risk in overall studies. Further studies were anticipated to be done.
\end{abstract}

Keywords: Meta-analysis; sexual dysfunction; premature ejaculation; 5-hydroxytryptamine; single nucleotide polymorphisms

Submitted Dec 01, 2019. Accepted for publication Mar 06, 2020.

doi: $10.21037 /$ tau.2020.03.39

View this article at: http://dx.doi.org/10.21037/tau.2020.03.39

\section{Introduction}

Premature ejaculation (PE) was one of the two most common male sexual disfunction, prevalence of $\mathrm{PE}$ was $20-30 \%$ all over the world (1). PE meant that Ejaculation occurs too quickly, either before vaginal penetration or $<1-2$ min afterwards, and PE could be classified as lifelong premature ejaculation (LPE) and secondary premature ejaculation (SPE). There has been a problem from the first sexual experience, and it's been going on for a lifelong in patients with LPE (1). Ejaculation always occurred within 1 minute of vaginal penetration from the first sexual experience, which was defined as LPE (2). It not only had a bad influence between the husband and wife, but also impacted the mental health and quality of life (3). Therefore, it was imperative to study premature ejaculation.

The etiology of PE was yet to be determined. PE has been recognized as a psychological block and discussed in relation to many factors in the past, for example: environmental, endocrine, neurobiological and genetic factors (4-6). Genetic factors accounted for around 30\% of all etiology (7), which was worth to study.

There is a specific protein transporter located in the cell membrane, called 5-hydroxytryptamine transporter 
(5-HTT). The function of 5-HTT is to promote reabsorbing serotonin from the synapse. However, the concentration of 5-hydroxytryptamine $(5-\mathrm{HT})$ in the synaptic cleft is related to ejaculation (8). As we all known, selective serotonin re-uptake inhibitors (SSRIs) could be used to delay the process of ejaculation (9), and has been used as primary therapeutic drug for PE currently (10). European Association of Urology (EAU) has suggested that the first-line treatment of LPE is pharmacotherapy, instead of behavioural treatment. Dapoxetine is the only drug approved for PE except for the USA (11). The 5 -hydroxytryptamine transporter-linked promoter region (5-HTTLPR) is a one of the 5-HTT gene, which has an effect on the function of 5-HTT (12). And there are two variant alleles: long (L) and short (S) allele respectively. The former has 44 base pairs (bps) more than the latter (13). And Janssen et al. considered that the ejaculation latency time is longer in men with SS and SL genotype than LL genotype (14). However, Safarinejad et al. showed a completely opposite view, considered that carriers of SS genotype had increased the risk of PE (15). These studies reported inconsistent and conflicting results, and the strength of evidence was not enough because the sample size was small in these studies. Consequently, we did the meta-analysis of overall currently authoritative articles to delve the possible relationships between 5-HTTLPR gene polymorphism with LPE risk. Then subgroup analysis has been done by ethnicity and control source. We also explored the association between 5-HTTLPR gene polymorphism and SPE risk, but there was not enough evidence to support the strength of the conclusion.

\section{Methods}

\section{Search strategy}

We performed a systematic search of Embase, PubMed and Cochrane Library databases for studies on 5-HTTLPR polymorphism and the susceptibility of LPE up to Sept, 2019. The key words and medical subject headings used for searching were 'premature ejaculation', 'early ejaculation', 'rapid ejaculation', 'polymorphism', 'serotonin', '5-HT', and '5-HTTLPR'. There was not any restriction on the sample size. We also have done a manual search of all retrieved reference to get the original text and reviewed them.

\section{Inclusion and exclusion criteria}

All studies we have included must meet the follow requirements: (I) the studies were associated with the theme: the association between 5-HTTLPR gene polymorphism and LPE risk; (II) case-control study; (III) there was similar characteristic between case group and health control in addition to the content of the study; (IV) the studies were consistent in Hardy-Weinberg equilibrium (HWE). These studies were excluded as follow: (I) the data was incomplete; (II) the type of study was abstract, review and comment; (III) the patient with other disease, such as diabetes, hypertension, melancholia or other sexual dysfunction, for example: erectile dysfunction, lukewarm sex.

\section{Data abstraction}

The patients were come from all over the world, and there was no repetition of the crowd among the studies. We have collected the relevant information needed for the study as follows: the family name of the lead author, the time of publication, nationality of patients, ethnicity, size of the sample, genotype distributions and the allele frequency in cases/controls. The quality of the included researches were evaluated by The Newcastle-Ottawa Scale (NOS) (16), and the selection, exposure and comparability of study were evaluated.

\section{Statistical analysis}

The abstracted data were analyzed with Stata 12.0 software. The publication bias was assessed by Egger's test and Begg's funnel plot (17). The stability and the effect of individual study on the overall odds ratios were determined by performing a sensitivity analysis. We also performed the NOS scale of case-control to assess the quality of the included researches. ORs (odds ratios) with $95 \%$ confidence intervals (CIs) was measured to evaluate the relativity between LPE risk and the polymorphism of the 5-HTTLPR gene. We calculated the total ORs by dominant model $(\mathrm{LL}+\mathrm{LS} v s . \mathrm{SS})$, recessive model (LL vs. LS+SS), homozygote model (LL vs. SS), heterozygote model (LS vs. SS), and allelic contrast (L-allele $v s$. S-allele) severally. The chi-square based on $\mathrm{Q}$ statistic was performed to check the heterogeneity among the studies, and result was recognized as significant at $\mathrm{P}<0.05$. When the $\mathrm{I}^{2}<50 \%$, indicated that there was no significant heterogeneity and the fixed-effects model (Mantel-Haenszel method) would be used (18). And we performed the random-effects model (DerSimonian and Laird method) when the heterogeneity of the data could not be explained $\left(\mathrm{P}<0.05, \mathrm{I}^{2}>50 \%\right)(19)$. The $Z$-test was 


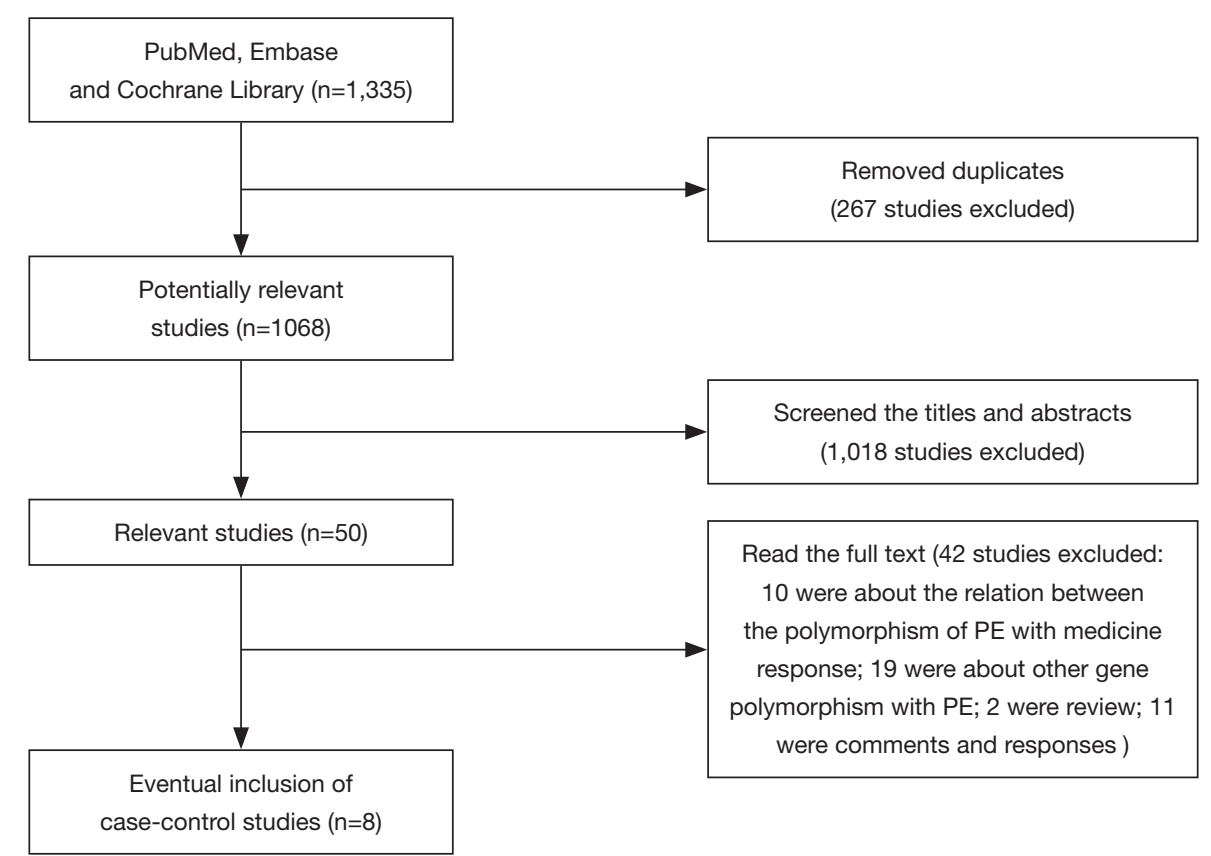

Figure 1 Flowchart illustrating the search strategy for 5-HTTLPR polymorphism and the risk of LPE.

performed to evaluate the meaning of the overall ORs, and statistically significant was observed with $\mathrm{P}<0.05$. We also made the subgroup analysis by the ethnicity of patients and control source respectively.

\section{Results}

\section{Studies characteristics}

A total of 1,068 potentially relevant articles were searched by systematic retrieval from the PubMed, Embase and Cochrane Library databases. As showed in Figure 1, full texts of 50 original articles on 5-HTTLPR gene polymorphism related to LPE were retrieved after screening the titles and abstracts. We excluded 42 studies: 10 were about the relation between the polymorphism of PE with medicine response; 19 were about other single nucleotide polymorphisms (SNPs) with PE; 2 were review; 11 were comments and responses. Finally, our meta contained 8 studies, a total of 898 LPE patients and 706 health controls $(14,15,20-25)$. The basic characteristics of all studies were showed in Table 1. All studies were consistent with the HardyWeinberg equilibrium (HWE). In these studies, 4 were conducted on Caucasian descendants, 3 on Asian descendants, and only one was conducted on African population. The same genotyping method by polymerase chain reaction based
(PCR)-restriction fragment length polymorphism (PFLP) was used in all articles we have included.

\section{Meta-analysis}

Table 2 listed the main results of the meta-analysis of 5-HTTLPR gene polymorphism and the susceptibility of LPE, as well as the results of subgroup analysis.

\section{Relationship between 5-HTTLPR polymorphism and susceptibility of LPE}

The pooled studies indicated that there was no significant relationship between the two over the different genetic models (Figure 2). According to the high heterogeneity $\left(\mathrm{I}^{2}>50 \%\right)$ in all models, the subgroup analyses were performed as followed.

\section{Relationship between 5-HTTLPR polymorphism and the population risk classified by ethnicity}

In this part, we found that there was significant association between 5-HTTLPR polymorphism and the risk of LPE in Caucasian population. The homozygous genetic models showed the significant result $(\mathrm{OR}=0.635,95 \%$ CI: $0.417-0.958, \mathrm{I}^{2}=0.311, \mathrm{P}=0.035$ ) in Figure 3, and we 
Table 1 Main characters of studies included in this meta-analysis

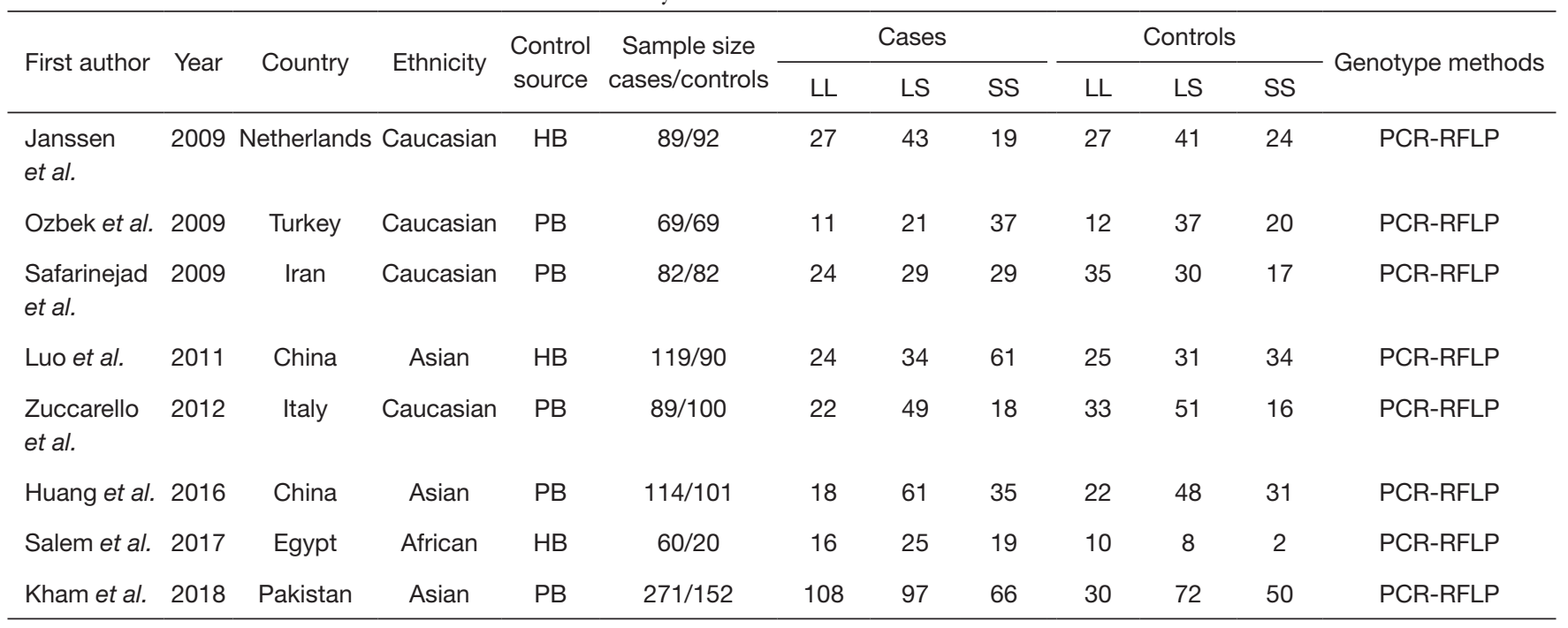

HB, hospital based; PB, population based; PCR, polymerase chain reaction; RFLP, restriction fragment length polymorphism.

also found positive result in Asians population in allelic genetic model $\left(\mathrm{OR}=0.656,95 \%\right.$ CI: $0.539-0.799, \mathrm{I}^{2}=0.435$, $\mathrm{P}<0.001$ ) (Figure 4). In addition, we also found significant association between the risk of LPE in African population and 5-HTTLPR gene polymorphism in Homozygous model $\left(\mathrm{OR}=0.168,95 \%\right.$ CI: $\left.0.032-0.884, \mathrm{I}^{2}=0, \mathrm{P}=0.035\right)$ and allelic contrast $\left(\mathrm{OR}=0.388,95 \%\right.$ CI: $0.180-0.834, \mathrm{I}^{2}=0$, $\mathrm{P}=0.015)$, which indicated that people with SS genotype and $\mathrm{S}$ allele were more likely to get LPE in different country. There's only one study (24) described the relationship in African population. So there's not enough evidence to show the relationship.

\section{Relationship between 5-HTTLPR polymorphism and PB and $\mathrm{HB}$ population risk}

People in population based (PB) were more likely to get LPE in allelic genetic model $(\mathrm{OR}=0.746,95 \% \mathrm{CI}$ : $0.576-0.967, \mathrm{I}^{2}=0.562, \mathrm{P}=0.027$ ) (Figure 5). Otherwise, no significantly different associations could be observed in different genetic models in hospital based (HB).

\section{Relationship between 5-HTTLPR polymorphism and SPE population risk}

In subgroup analysis, 2 studies $(22,25)$ were further divided the PE into LPE and SPE. The results also showed that no significantly different associations could be observed in SPE (Figure 6).

\section{Sensitivity analysis and publication bias}

We performed a sensitivity analysis to evaluate the effect of a single study on the total results, which showed that there was not any study impacted the pooled ORs significantly. This demonstrated that combining results were reliable (Figure 7). We also evaluated the publication bias by Egger's test and Begg's funnel plot as shown in Figure 8, the shapes of all models were symmetric, which indicated that no evidence could be used to affirm that there was publication bias.

\section{Discussion}

This was a meta-analysis of 5-HTTLPR polymorphism and the susceptibility of LPE. We found that SS genotype of 5-HTTLPR gene polymorphism increased susceptibility to LPE in Caucasian population, which was similar to the result by Zhu et al. (26), moreover, the risk of LPE also has increased with S-allele in Asian. However, we didn't find a significant association between 5-HTTLPR gene polymorphism and LPE in overall studies. These results were different with Zhu et al. In addition, for the people from PB, S-allele also increased susceptibility to LPE. So we suggested that SS genotype and S-allele of 5-HTTLPR gene polymorphism were risk factors for LPE.

On the one hand, 5-HTTLPR polymorphism was related to many diseases. The bio-psycho-social model emphasized that the influence of stress environment on children's question behavior was restricted by the biological 


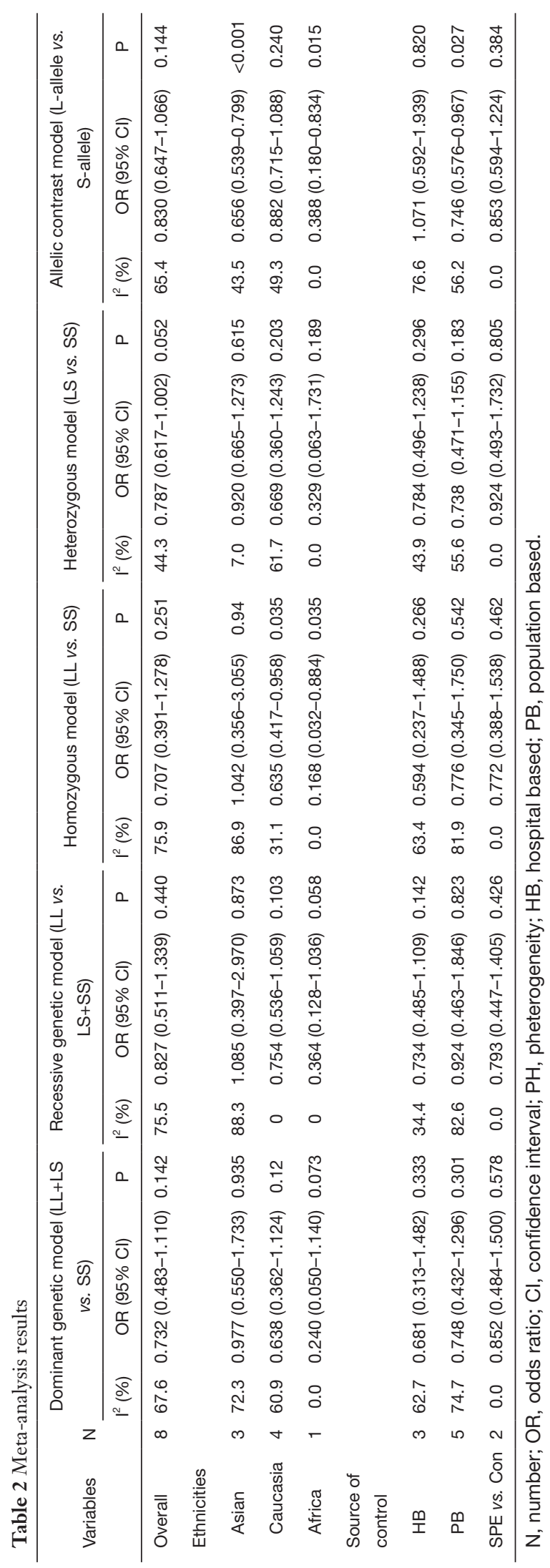

genetic basis, especially the 5-HT system, which was related to psychological function such as depression, and had important influence on it (27). Deuschle et al. found that the risk of insomnia were higher in people with $\mathrm{S}$ allele, instead of control group (28). In 2010, a metaanalysis examined studies from European and East Asian populations, confirming that there was a correlation between 5-HTTLPR and depression (29). On the other hand, there were also many gene polymorphism closely related to PE, Luo et al. found that LPE was associated with the $5-\mathrm{HT}_{2 \mathrm{C}}$ receptor gene polymorphism, and people with the $-759 \mathrm{~T}$ or $-697 \mathrm{C}$ genotype were more likely to have $\mathrm{PE}$ (30). Jern et al. found that the polymorphism of 5-HT also had a huge influence in the time of ejaculation, and suggested that people with $\mathrm{G}$ allele had a shorter time than the control group when having sexual intercourse (31).

However, most of the research was still about the 5-HTTLPR, which was a functional repeat polymorphism. It was on chromosome 17, and was part of the serotonin transporter gene SLC6A4. There were two variant alleles which were called long (L) and short (S) allele. The former had 44 base pairs (bps) more than the latter. The possible mechanism of the relationship between LPE and 5-HTTLPR polymorphism was that the $\mathrm{L}$ and $\mathrm{S}$ alleles could regulate the transcriptional activity of the 5-HTT promoter respectively, and the transcriptional activities of different genotypes were different. Therefore, we can make the 5-HT indexes different in human body by affecting the concentration of 5-HTT mRNA in human body, the reabsorption of 5-HT at presynaptic membrane and the synthesis of 5-HTT protein, which could affect the intensity and duration on ejaculation by 5 -HT signaling pathway. It has been found that the transcriptional activity of short type (S) allele was much lower than long type (L) allele $(12,32)$.

In these studies we have included, just one study discussed the relationship with Chinese and suggested that triallelic way should be used in studying 5-HTTLPR (20). In addition, Safarinejad et al. and Zuccarello et al. also used triallelic approach to study 5-HTTLPR. They discussed the SNP $\operatorname{rs} 25531(\mathrm{~A} / \mathrm{G})$ and made a distinction between $\mathrm{L}_{\mathrm{G}}$ and $\mathrm{L}_{\mathrm{A}}$. Safarinejad et al. thought that men who carried $\mathrm{S} / \mathrm{S}, \mathrm{L}_{\mathrm{G}} / \mathrm{L}_{\mathrm{G}}$ or $\mathrm{S} / \mathrm{L}_{\mathrm{G}}$ had higher risk of PE (15). But Zuccarello et al. found that there were not any relationship between the two (25). So the further research was required to confirm the correlation between LPE and 5-HTTLPR polymorphism.

Firstly, we analyzed the association between the case group and health volunteers, and we discovered that the 
Study

ID

Janssen et al (2009)

Ozbek et al (2009)

Safarinejad et al (2009)

Luo et al (2011)

Zuccarello et al (2012)

Huang et al (2016)

Salem et al (2017)

Kham,H.L et al (2018)

Overall $(\mathrm{I}-$ squared $=65.4 \%, \mathrm{p}=0.005)$

NOTE: Weights are from random effects analysis

.22

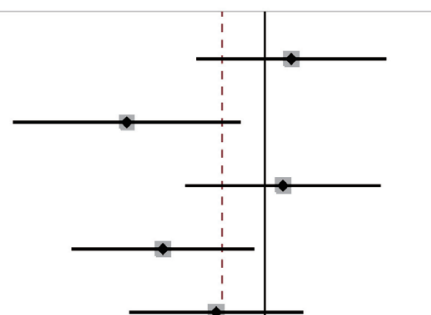

$1.12(0.74,1.70) \quad 12.89$

$0.55(0.33,0.90) \quad 11.18$

$1.08(0.71,1.65) \quad 12.64$

$0.64(0.43,0.96) \quad 13.24$

$0.81(0.55,1.18) \quad 13.67$

$0.89(0.60,1.30) \quad 13.59$

$2.11(0.98,4.54) \quad 6.93$

$0.56(0.42,0.75) \quad 15.85$

$0.83(0.65,1.07) \quad 100.00$

Figure 2 Forest plot of 5-HTTLPR polymorphism and LPE (allelic genetic contrast L-allele vs. S-allele).

Study

ID
$\%$

OR $(95 \% \mathrm{CI}) \quad$ Weight

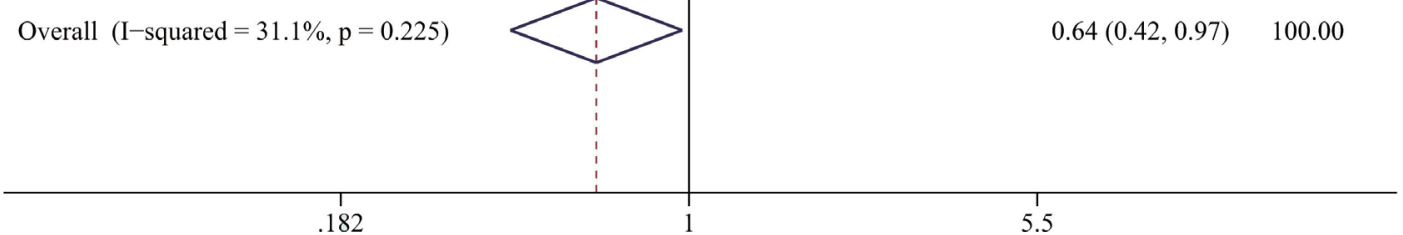

Figure 3 Caucasian population subgroup meta-analysis was held for the association between 5-HTTLPR polymorphism and LPE (homozygous genetic model LL vs. SS). 
Study

ID
$\%$

OR $(95 \% \mathrm{CI}) \quad$ Weight

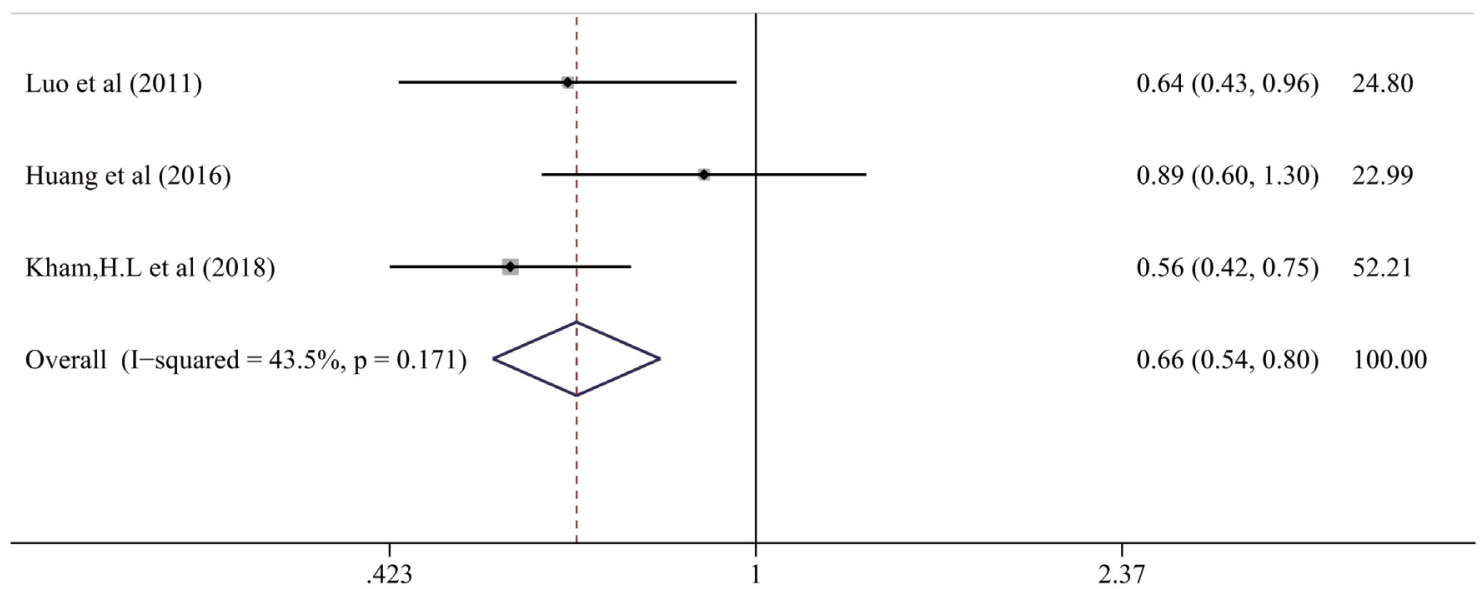

Figure 4 Asian population subgroup meta-analysis was held for the association between 5-HTTLPR polymorphism and LPE (allelic genetic contrast L-allele vs. S-allele).

Study

ID
$\%$

OR $(95 \% \mathrm{CI}) \quad$ Weight

\begin{tabular}{|c|c|c|}
\hline Ozbek et al (2009) & $0.55(0.33,0.90)$ & 15.62 \\
\hline Safarinejad et al (2009) & $1.08(0.71,1.65)$ & 18.37 \\
\hline Zuccarello et al (2012) & $0.81(0.55,1.18)$ & 20.46 \\
\hline Huang et al (2016) & $0.89(0.60,1.30)$ & 20.29 \\
\hline Kham,H.L et al (2018) & $0.56(0.42,0.75)$ & 25.26 \\
\hline Overall $(\mathrm{I}-$ squared $=56.2 \%, \mathrm{p}=0.058)$ & $0.75(0.58,0.97)$ & 100.00 \\
\hline NOTE: Weights are from random effects analysis & & \\
\hline
\end{tabular}

Figure 5 Population based subgroup meta-analysis was held for the association between 5-HTTLPR polymorphism and LPE (allelic genetic contrast L-allele vs. S-allele).

risk of LPE was not associated with the 5-HTTLPR gene polymorphism in five genetic models, which is different with Zhu et al. (26). So we performed subgroup analysis to explore the relationship, the result showed SS genotype was a risk factor of LPE in Caucasian. In addition, we also found that S-allele also could increase the risk of LPE in Asian. So we suggested that SS genotype and S-allele might be a risk factor for LPE, but needed more large sample statistics 
Study

ID
$\%$

OR $(95 \% \mathrm{CI}) \quad$ Weight

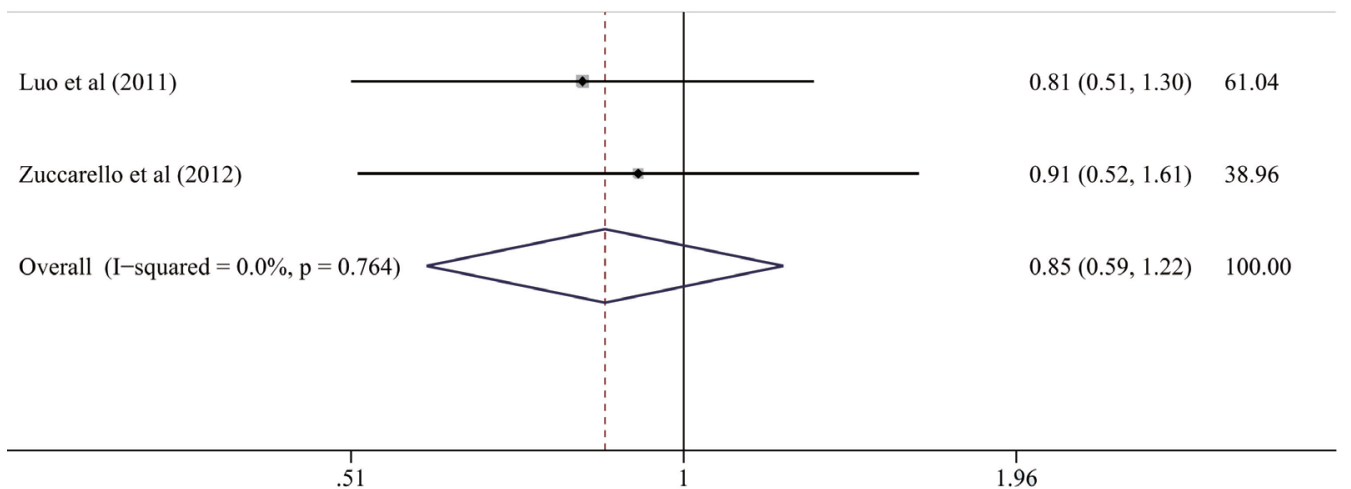

Figure 6 Forest plot of 5-HTTLPR polymorphism and SPE (allelic genetic contrast L-allele vs. S-allele).

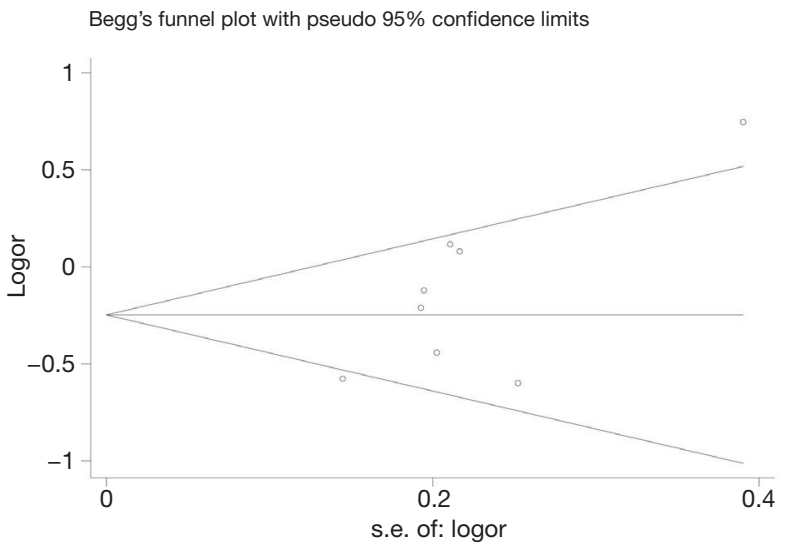

Figure 7 Sensitivity analysis (allelic contrast L-allele vs. S-alele).

to support the conclusion. Otherwise, we also detected the same correlation between 5-HTTLPR polymorphism and susceptibility to LPE in PB population in allelic genetic contrast. Our meta-analysis may help doctor to discover high-risk population of LPE and promote the research of the polymorphism of LPE, it also could be helpful for the treatment of LPE.

LPE is a multifactorial disorder (33). It is mediated by complex interactions of the neurobiological (34), genetic (35), endocrine (36) and psychological (37) factors, which are considered as the significant risk factors for LPE. Endocrine factor might be one of the most vital factors through hormonal regulation of the ejaculatory process. Increasing evidence suggested that testosterone, the key hormone of

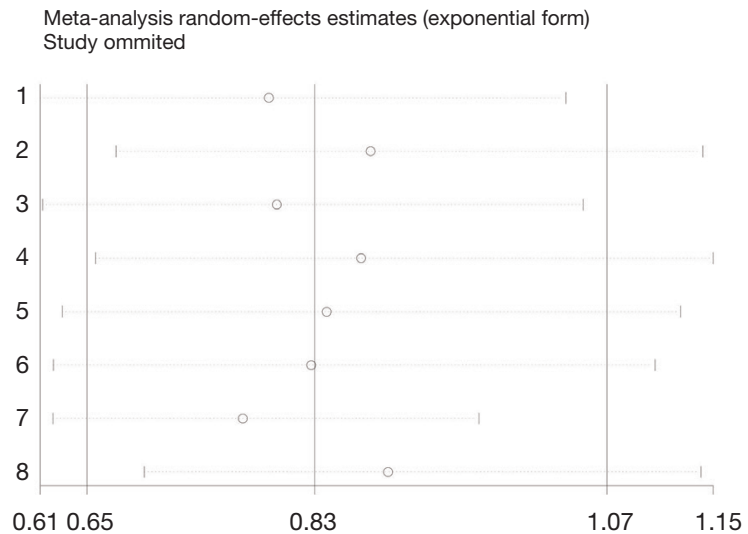

Figure 8 Funnel plot (allelic contrast L-allele $v s$. S-allele).

male sexuality, is involved in the regulation of ejaculatory reflex (38). Androgens influence ejaculatory reflex by several mechanisms: (I) acting on the various central and peripheral nucleuses which are related to the ejaculatory pathways, (II) altering the expression of several mediators which mediate the ejaculatory reflex, and (III) regulating the different pathways which are associated with the contractility of male genital tract (39). Furthermore, recently it was suggested that elevated testosterone and reduced estradiol could enhance the parasympathetic excitation, and as a consequence, ejaculatory latency time will be shortened (38).

Treatment for LPE has progressed since the 1930s. Praejaculin has been launched in 1932 as the first oral drug 
for PE (40). Although dapoxetine had weak ejaculation delaying effect, on-demand use of $30 \mathrm{mg}$ dapoxetine is the first registered oral drug for the treatment of LPE (9). Fortacin topical Spray has been the second registered drug for the treatment of LPE (41). Moreover, there are also many Off-label drugs to treat LPE, especially the selective serotonin reuptake inhibitors (42). Furthermore, ondemand treatment with over the counter topical anesthetics is well established and is effective in delaying ejaculation in men with LPE recently (37). In addition to drug therapy, psychological and psychosexual behavioural therapy has become more and more important for LPE patients (43). It is vital during the management stage to set treatment goals with each patient and partner if appropriate, in order to better guide therapeutic actions.

Combined therapy including pharmacological and nonpharmacological treatment may be the most effective way of treating patients with PE in the future (44). As the effects of $\mathrm{PE}$ on a patient and their partner's is multifactorial, exclusive treatment may fail to address certain patient needs. In particular, sole pharmacological treatment may be unable to address significant emotional distress surrounding $\mathrm{PE}$, interpersonal relationships, and unrealistic expectations from patients. Psychological and psychosexual behavioural strategies may similarly fall short in adequately extending IELT in patients or increasing the patient's perceived control over ejaculation. A suggested solution to providing holistic patient care is combination or integrated therapy. A study found that combination therapy of Dapoxetine and psychosexual behavioural treatment was more effective than pharmacological treatment alone in improving IELT in patients with LPE (45), which indicated the promise of combination therapy. A combined treatment of pharmacological, and non-pharmacological management may be superior to pharmacological treatment alone in providing patients with holistic and effective care.

On the one hand, compared with Zhu et al.'s research, the data of our study was more abundant and latest. Furthermore, we included 8 studies with 1,604 subjects, containing $898 \mathrm{LPE}$ patients and 706 healthy controls, which made our results more reliable. In addition, we also performed the sensitivity analysis and Begg's test to make our results more credible.

On the other hand, our study also had some disadvantages need to be improved. The size of the sample was still too small to draw any conclusions. So there needed more researches to confirm the conclusion. In our study, the heterogeneity was significant which reduced the reliability of results. All the same, the heterogeneity was accepted in stratified analysis by ethnicity and suggested strong correlation.

\section{Conclusions}

Generally speaking, in our meta-analysis of 8 reliable studies, we found that SS genotype of 5-HTTLPR gene polymorphism increased susceptibility to LPE in Caucasian population, and the S-allele gene was also a risk factor for LPE in Asian. So it can be indicated that SS genotype and S-allele of 5-HTTLPR gene polymorphism were risk factors for LPE. However, no significant correlation was observed between 5-HTTLPR gene polymorphism and LPE in overall studies. More researches were needed to confirm these conclusions.

\section{Acknowledgments}

We sincerely thank Chao Li (Tianjin Medical University General Hospital) and Yu Wang (Tianjin Medical University General Hospital) for the help and support of the meta-analysis.

Funding: This work was supported by Zhao Yi-Cheng Medical Science Foundation (Grant no. ZYYFY2018031).

\section{Footnote}

Conflicts of Interest: All authors have completed the ICMJE uniform disclosure form (available at http://dx.doi. org/10.21037/tau.2020.03.39). The authors have no conflicts of interest to declare.

Ethical Statement: All authors are accountable for all aspects of the work in ensuring that questions related to the accuracy or integrity of any part of the work are appropriately investigated and resolved.

Open Access Statement: This is an Open Access article distributed in accordance with the Creative Commons Attribution-NonCommercial-NoDerivs 4.0 International License (CC BY-NC-ND 4.0), which permits the noncommercial replication and distribution of the article with the strict proviso that no changes or edits are made and the original work is properly cited (including links to both the formal publication through the relevant DOI and the license). 
See: https://creativecommons.org/licenses/by-nc-nd/4.0/.

\section{References}

1. Hatzimouratidis K, Amar E, Eardley I, et al. Guidelines on Male Sexual Dysfunction: Erectile Dysfunction and Premature Ejaculation. Eur Urol 2010;57:804-14.

2. Serefoglu EC, McMahon CG, Waldinger MD, et al. An Evidence-Based Unified Definition of Lifelong and Acquired Premature Ejaculation: Report of the Second International Society for Sexual Medicine Ad Hoc Committee for the Definition of Premature Ejaculation. J Sex Med 2014;11:1423-41.

3. Rosen RC, Althof S. Impact of Premature Ejaculation: The Psychological, Quality of Life, and Sexual Relationship Consequences. J Sex Med 2008;5:1296-307.

4. Corona G, Jannini EA, Mannucci E, et al. Different Testosterone Levels Are Associated with Ejaculatory Dysfunction. J Sex Med 2008;5:1991-8.

5. Waldinger MD. The Neurobiological Approach to Premature Ejaculation. J Urol 2002;168:2359-67.

6. Jern P, Santtila P, Witting K, et al. Premature and Delayed Ejaculation: Genetic and Environmental Effects in a Population-Based Sample of Finnish Twins. J Sex Med 2007;4:1739-49.

7. Jern P, Santtila P, Johansson A, et al. Evidence for a genetic etiology to ejaculatory dysfunction. Int $j$ Impot Res 2009;21:62-7.

8. Qian Y, Melikian HE, Rye DB, et al. Identification and characterization of antidepressant-sensitive serotonin transporter proteins using site-specific antibodies. J Neurosci 1995;15:1261.

9. Pryor JL, Althof SE, Steidle C, et al. Efficacy and tolerability of dapoxetine in treatment of premature ejaculation: An integrated analysis of two double-blind, randomised controlled trials. Lancet 2006;368:929-37.

10. Althof SE, McMahon CG, Waldinger MD, et al. An Update of the International Society of Sexual Medicine's Guidelines for the Diagnosis and Treatment of Premature Ejaculation (PE). Sex Med 2014;2:60-90.

11. Erectile Dysfunction, Premature Ejaculation, Penile Curvature and Priapism.

12. Smith GS, Lotrich FE, Malhotra AK, et al. Effects of Serotonin Transporter Promoter Polymorphisms on Serotonin Function. Neuropsychopharmacology 2004;29:2226-34.

13. Bradley SL, Dodelzon K, Sandhu HK, et al. Relationship of serotonin transporter gene polymorphisms and haplotypes to mRNA transcription. Am J Med Genet B
Neuropsychiatr Genet 2005;136B:58-61.

14. Janssen PKC, Bakker SC, et al. Serotonin Transporter Promoter Region (5-HTTLPR) Polymorphism is Associated with the Intravaginal Ejaculation Latency Time in Dutch Men with Lifelong Premature Ejaculation. J Sex Med 2009;6:276-84.

15. Safarinejad MR. Polymorphisms of the Serotonin Transporter Gene and Their Relation to Premature Ejaculation in Individuals from Iran. J Urol 2009;181:2656-61.

16. Stang A. Critical evaluation of the Newcastle-Ottawa scale for the assessment of the quality of nonrandomized studies in meta-analyses. Eur J Epidemiol 2010;25:603-5.

17. Hayashino Y, Noguchi Y, Fukui T. Systematic Evaluation and Comparison of Statistical Tests for Publication Bias. J Epidemiol 2005;15:235-43.

18. DerSimonian R, Laird N. Meta-analysis in clinical trials revisited. Contemp Clin Trials 2015;45:139-45.

19. Mantel N, Haenszel W. Statistical aspects of the analysis of data from retrospective studies of disease. J Natl Cancer Inst 1959;22:719-48.

20. Huang Y, Zhang X, Gao J, et al. Biallelic and Triallelic 5-Hydroxytyramine Transporter Gene-Linked Polymorphic Region (5- HTTLPR) Polymorphisms and Their Relationship with Lifelong Premature Ejaculation: A Case-Control Study in a Chinese Population. Med Sci Monit 2016;22:2066-74.

21. Khan HL, Bhatti S, Abbas S, et al. Serotonin transporter (5-HTTLPR) genotypes and trinucleotide repeats of androgen receptor exert a combinatorial effect on hormonal milieu in patients with lifelong premature ejaculation. Andrology 2018;6:916-26.

22. Luo SW, Wang F, Xie ZY, et al. Study on the correlation of the 5-HTTLPR polymorphism with premature ejaculation in Han Chinese population. Beijing Da Xue Xue Bao Yi Xue Ban 2011;43:514.

23. Ozbek E, Tasci AI, Tugcu V, et al. Possible association of the 5-HTTLPR serotonin transporter promoter gene polymorphism with premature ejaculation in a Turkish population. Asian J Androl 2009;11:351-5.

24. Salem AM, Kamel II, Rashed LA, et al. Effects of paroxetine on intravaginal ejaculatory latency time in Egyptian patients with lifelong premature ejaculation as a function of serotonin transporter polymorphism. Int $\mathrm{J}$ Impot Res 2017;29:7-11.

25. Zuccarello D, Ghezzi M, Pengo M, et al. No Difference in 5-HTTLPR and Stin2 Polymorphisms Frequency Between Premature Ejaculation Patients and Controls. J 
Sex Med 2012;9:1659-68.

26. Zhu L, Mi Y, You X, et al. A meta-analysis of the effects of the 5-hydroxytryptamine transporter gene-linked promoter region polymorphism on susceptibility to lifelong premature ejaculation. PLoS One 2013;8:e54994.

27. Calkins SD, Propper C, Mills-Koonce WR. A biopsychosocial perspective on parenting and developmental psychopathology. Dev Psychopathol 2013;25:1399-414.

28. Deuschle M, Schredl M, Schilling C, et al. Association between a serotonin transporter length polymorphism and primary insomnia. Sleep 2010;33:343-7.

29. Clarke H, Flint J, Attwood AS, et al. Association of the 5- HTTLPR genotype and unipolar depression: a metaanalysis. Psychol Med 2010;40:1767-78.

30. Luo S, Lu Y, Wang F, et al. Association between Polymorphisms in the Serotonin 2C Receptor Gene and Premature Ejaculation in Han Chinese Subjects. Urol Int 2010; 85: 204-8.

31. Jern P, Westberg L, Johansson A, et al. A Study of Possible Associations Between Single Nucleotide Polymorphisms in the Serotonin Receptor 1A, 1B, and 2C Genes and Self-Reported Ejaculation Latency Time. J Sex Med 2012;9:866-72.

32. Murphy DL, Lerner AG, Lesch KP. Serotonin transporter: gene, genetic disorders, and pharmacogenetics. Molecular Interventions 2004;4:109-23.

33. Giuliano F, Clément P. Physiology of Ejaculation: Emphasis on Serotonergic Control. Eur Urol 2005;48:408-17.

34. Borgdorff A J, Bernabé J, Denys P, et al. Ejaculation Elicited by Microstimulation of Lumbar Spinothalamic Neurons. Eur Urol 2008;54:449-56.

Cite this article as: Zhou K, Song Y, Lu Y, Yang Y, Wang $\mathrm{X}$, Liu K, Liu X. Association between 5 ta-hydroxytryptamine transporter gene-linked promoter region polymorphism and the susceptibility of lifelong premature ejaculation: a meta-analysis involving 1,604 subjects. Transl Androl Urol 2020;9(3):1394-1404. doi:10.21037/tau.2020.03.39
35. Janssen P K C, Bakker S C, Rã Thelyi J, et al. Serotonin Transporter Promoter Region (5-HTTLPR) Polymorphism is Associated with the Intravaginal Ejaculation Latency Time in Dutch Men with Lifelong Premature Ejaculation. J Sex Med 2009;6:276-84.

36. Waldinger M D. The pathophysiology of lifelong premature ejaculation. Transl Androl Urol 2016;5:424-33.

37. Althof SE, Mcmahon CG, Waldinger MD, et al. An Update of the International Society of Sexual Medicine's Guidelines for the Diagnosis and Treatment of Premature Ejaculation (PE). J Sex Med 2014;11:1392-422.

38. Wu F, Chen T, Mao S, et al. Levels of estradiol and testosterone are altered in Chinese men with sexual dysfunction. Andrology 2016;4:932-8.

39. Corona G, Jannini EA, Vignozzi L, et al. The hormonal control of ejaculation. Nat Rev Urol 2012;9:508-19.

40. Waldinger MD. Drug treatment options for premature ejaculation. Expert Opin Pharmacother 2018;19:1077-85.

41. Porst H, Burri A. Fortacin ${ }^{\mathrm{TM}}$ Spray for the Treatment of Premature Ejaculation. Urologia 2017;84:1-10.

42. Csoka A B, Csoka A, Bahrick A, et al. Persistent sexual dysfunction after discontinuation of selective serotonin reuptake inhibitors. J Sex Med 2008;5:227-33.

43. Melnik T, Althof S, Atallah AN, et al. Psychosocial interventions for premature ejaculation. Cochrane Database Syst Rev 2011;(8):CD008195.

44. Gillman N, Gillman M. Premature Ejaculation: Aetiology and Treatment Strategies. Medical Sciences 2019;7:102.

45. Cormio L, Massenio P, La Rocca R, et al. The Combination of Dapoxetine and Behavioral Treatment Provides Better Results than Dapoxetine Alone in the Management of Patients with Lifelong Premature Ejaculation. J Sex Med 2015;12:1609-15. 